\title{
NITROXYNIL UNCOUPLES OXIDATIVE PHOSPHORYLATION IN THE CELL MITOCHONDRIA AND A DRUG WHEREVER INJECTABLES ARE PREFERRED OVER DRENCHES
}

\author{
M. M. Rahman ", A. Kabir, S. Ahmed, M. K. Islam, M. S. Rahman, M. Alam, M. A. A. Mubeen, M. S. Yasmin, M. S. \\ Hossain, M. W. U. Haque and M. T. Mia
}

Department of Veterinary and Animal Sciences, University of Rajshahi, Rajshahi-6205, Bangladesh.

\begin{abstract}
In the absence of effective vaccines and because of practical limitations in management options to control the snail intermediate hosts, the control of liver fluke infection and disease in livestock relies heavily on the use of flukicidal anthelmintics. Nitroxynil is a nitrate derivative from benzene compounds and presents a flukicide effect and is commonly used as the one with best spectrum from all the nitrate derivative trematocides. The drug is in fact, a low spectrum anthelmintic effective against fascioliasis, an important parasitic disease caused by flukes like Fasciola hepatica, Fasciola gigantica, affecting significantly the ruminant production by means of reducing the growth, conversion rate, milk production, quality and quantity of meat and reproduction. Nitroxynil also does hold efficacy against few roundworms mainly bloodsucking species as well as certain myiasis. It is not effective against most of the tape worms or external parasites. It is chemically constitute of yellow benzene crystals, slightly soluble in water and soluble in organic solvents, almost odorless and is characterized for being a stable solution, but it precipitates in presence of calcium and other salts. It is marketed as bright orange-red injectable solution due that by this route is six times more efficient than by oral route. Nitroxynil is a safe drug and it can be used at any stage of pregnancy. It does not affect fertility, gestation or fetus formation and in no way impede the reproductive performance of stallions. It's presented as two salts, nitroxynil megaglumine and nitroxynil eglumine. The nitroxynil in salt is hydrosoluble having neutral $\mathrm{p}^{\mathrm{H}}$ and is exclusively administered to animals by subcutaneous route. The flukicide resistance phenomenon is already present in many countries in the same way that resistance against other anthelmintic drugs is spreading around worldwide. Because of the absence of new drugs against fluke infections, it is necessary to prove and compare the efficacy of the anthelmintics to prevent resistance development. In view of that we endeavored elucidating the latest progress of one such widely used flukicide nitroxynil.
\end{abstract}

Keywords: Nitroxynil, pharmacokinetics, interactions, flukicides, fascioliasis, efficacy.

\section{Introduction:}

The fasciolicides in common use today or in the more recent past fall into five main chemical groupings: (A) Halogenated phenols: e.g. nitroxynil, hexachlorophene, niclofolan and bithionol; (B) Salicylanilides: e.g. closantel, oxyclozanide, rafoxanide and brotianide; (C) Benzimidazoles: triclabendazole, luxabendazole, mebendazole and albendazole; (D) Sulphonamides: e.g. clorsulon and (E) Phenoxyalkanes: e.g. diamphenethide. Conversely liver fluke particularly Fasciola hepatica in temperate countries and its counterpart Fasciola gigantica in the tropics remains one of the single most important helminth parasites of livestock around the world, although it does not go with the collective implications of nematodes. Disease, as a result of liver fluke, not only poses a threat to animal welfare, but also is associated with major economic loss to the farmer. Loss may be through reduced weight gain or milk production, a predisposition to diseases or mortality. Poor weight gain with compromised production of animal is fully linked with hepatic damages as evidenced by increased GGT, the enzyme that is related to the presence of adult flukes into the bile ducts as well as augmented AST enzyme, which reflects the migration of the immature flukes throughout the liver (Maria et al., 2010). The fasciolicide drugs are the key for developing any strategies for controlling fascioliasis in livestock and in man. Infection with both $F$. hepatica and $F$. gigantica may also occur in man, occasionally causing large scale epidemics involving hundreds of people (Chen, 1990; Massoud, 1990). Now a days in the absence of new anthelmintics with unique modes of action, parasite control is increasingly getting difficult and sometimes exclusively becoming reliant on combinations of existing broad spectrum nematocides and flukicides to increase combined spectrum of activity and efficacy against early immature stages as well as adult liver flukes in animals and man.

Nitroxynil is a low spectrum flukicide and nematicide used on cattle, sheep and goats. It is available and used mostly in ruminants in the form of injectables, often in combination with other anthelmintics and the efficacy against a specific parasite depends on the delivery form and on the dose administered. It is not used in poultry and horses. Nitroxynil, 4hydroxy-3-iodo-5-nitrobenzonitrile, which is a halogenated phenol (Whelan et al., 2010; Ghoneim et al., 2006), acts by stopping oxidative phosphorylation in the cell mitochondria. This disturbs the production of ATP, thus impairing motility of the parasites (Boray et al., 1968; Rapic et al., 1998). Nitroxynil binds very strongly to plasma proteins (Alvinerie et al., 1991), indicating that oral ingestion is the most likely route. In the EU nitroxynil is the only flukicide with an established MRL for bovine and ovine milk. The maximum residue limit (MRL) is in fact, the maximum concentration of residue accepted by the European Union (EU) in a food product obtained from an animal that has received a veterinary medicine

\footnotetext{
*Corresponding e-mail address: mahbub.unimi@gmail.com
} 


\section{M. Rahman and others}

or that has been exposed to a biocidal product for use in animal husbandry. Nitroxynil is less used in pets; however, in dogs it could kill Ancylostoma spp. and Uncinaria spp. Recent SEM examination of nitroxynil-treated flukes showed limited areas of tegument sloughing in the tail region. In more seriously affected specimens, the syncytium appeared stripped away to reveal the basal lamina. Disruption of the subtegumental tissues with spacing or flooding between the cells and breakdown of the cell bodies as well as some deeper lesions were also observed as the loss of tegument facilitated penetration of the drug to the exposed deeper tissues of the flukes (Omranet al., 2015, McKinstry et al., 2007).

In order to control the impact of fluke, producers have over many years routinely employed the use of flukicides. Of the currently available flukicides, for safety and efficacy, the first drug of choice for the treatment of human and animal fascioliasis is still the triclabendazole. This drug has the broadest activity against different stages of liver flukes with efficacy observed from two-day-old immature flukes through to mature adults (Boray et al., 1983). However, what makes triclabendazole critically important is in the treatment of acute fasciolisis in sheep, which is caused by the hepatic peregrinations of immature fluke (Boray, 1967; Fairweather and Boray, 1999a). Most of the other flukicides have activity against either adult ( $\geq 10$-12 week old) fluke only, e.g. oxyclozanide, albendazole, or adult and late immature ( $>6$ to 8 week-old) fluke, e.g. rafoxanide, closantel (Fairweather and Boray, 1999b). Triclabendazole resistance against liver fluke was first documented in Australia and later in Europe and South America (Overend and Bowen, 1995; Mitchell et al., 1998; Moll et al., 2000; Olaechea et al., 2011). Treatment of acute fascioliasis in sheep in areas where triclabendazole is no longer effective is problematic and a potential cause of serious welfare problems. Since the triclabendazole efficacy is getting compromised owing to the emergence of parasitic resistance, nitroxynil and other flukicides, such as closantel and oxyclozanide, have been shown to be effective against those resistant isolates of adult Fasciola sp (Coles and Stafford, 2001; McKinstry et al., 2009; Mooney et al., 2009). Nitroxynil, 4-hydro- 3-iodo-5-nitrobenzonitrile, one such crucial flukicide, is used in both cattle and sheep where it is equally effective against immature and adult fluke (Bishop, 2005).

\section{Efficacy and Dosing of nitroxynil}

Nitroxynil is highly effective against adult liver flukes Fasciola spp and against late immature stages ( $>6$ weeks) in cattle, sheep, goats and camelids. It is also effective against a few gastrointestinal roundworms e.g. Bunostomum spp., Hemonchus spp., Oesophagostomum spp. and Parafilariabovicola as well as against myiases caused by the sheep nasal bot fly Oestrus ovis. In contrast with many other anthelmintics e.g. imidazothiazoles, benzimidazoles, tetrahydropyrimidines, nitroxynil has a residual effect, i.e. it not only kills the parasites present in the host at the time of treatment, but protects against re-infestation for a period of time up to several weeks that depends on the dose and the specific parasite. Nitroxynil not effective against rumen flukes Paramphistomum spp., other roundworms such as lung worms e.g. Dictyocaulus spp. or eye worms e.g. Thelazia spp., tapeworms and other external parasites.

Table 1. The table indicates some usual dosing recommendations for nitroxynil issued by manufacturers or documented in the scientific literature.

\begin{tabular}{|c|c|c|c|c|}
\hline \multicolumn{5}{|c|}{ Dosing recommendations for Nitroxynil } \\
\hline Species & Parasites & Dose range & Standard average dose & Delivery \\
\hline \multirow[t]{3}{*}{$\begin{array}{l}\text { Cattle and } \\
\text { camelids }\end{array}$} & $\begin{array}{lll}\begin{array}{l}\text { Fasciola } \\
\text { gigantica }\end{array} & \text { hepatica, } & \text { Fasciola } \\
\end{array}$ & $12.5-13 \mathrm{mg} / \mathrm{kg}$ & $10 \mathrm{mg} / \mathrm{Kg}$ & Subcutaneous \\
\hline & Parafilaria bovicola & $20 \mathrm{mg} / \mathrm{kg}$ & $10 \mathrm{mg} / \mathrm{Kg}$ & Subcutaneous \\
\hline & $\begin{array}{l}\text { Gastrointestinal round worms like } \\
\text { Hemonchus contortus } \\
\text { Hemonchus placei } \\
\text { Oesophagostomum radiatum } \\
\text { Bunostomum phlebotomum }\end{array}$ & $7-12.5 \mathrm{mg} / \mathrm{kg}$ & $10 \mathrm{mg} / \mathrm{Kg}$ & Subcutaneous \\
\hline \multirow{3}{*}{$\begin{array}{l}\text { Sheep \& } \\
\text { Goat }\end{array}$} & Oestrus ovis & $20 \mathrm{mg} / \mathrm{kg}$ & $10 \mathrm{mg} / \mathrm{Kg}$ & Subcutaneous \\
\hline & Fasciola hepatica & $10-15 \mathrm{mg} / \mathrm{kg}$ & $10 \mathrm{mg} / \mathrm{Kg}$ & Subcutaneous \\
\hline & $\begin{array}{l}\text { Gastrointestinal round worms like } \\
\text { Hemonchus contortus }\end{array}$ & $7-12.5 \mathrm{mg} / \mathrm{kg}$ & $10 \mathrm{mg} / \mathrm{Kg}$ & Subcutaneous \\
\hline Swine & Fasciola hepatica & $10-13 \mathrm{mg} / \mathrm{Kg}$ & $10 \mathrm{mg} / \mathrm{Kg}$ & Subcutaneous \\
\hline
\end{tabular}

The drug is normally supplied in $10 \mathrm{ml}$ and $25 \mathrm{ml}$ amber glass vial with each $\mathrm{ml}$ contains Nitroxynil BP $250 \mathrm{mg}$. Commercial presentation of flasks of $10 \mathrm{ml}, 20 \mathrm{ml}, 50 \mathrm{ml}, 100 \mathrm{ml}, 250 \mathrm{ml}$ and $500 \mathrm{ml}$ is also available. Trodax and Dovenix are some original international brands where OXINIL, nitroxynil ${ }^{\circledR}$ etc. are local brands available in the markets. 
Besides the aforementioned standard dosage mentioned in the table 1, the drug is frequently applied to cattle, buffalo, goat and sheep at a rate of $10 \mathrm{mg}$ per $\mathrm{kg}$ weight, equivalent to $1 \mathrm{ml}$ per $25 \mathrm{~kg}$ of body weight subcutaneously. In case of acute infection by immature flukes the dose needs to be increased to 1.3 to $1.5 \mathrm{ml}$ per $25 \mathrm{~kg}$ of body weight. In case of massive infestation the drug needs to be repeated after 3 weeks. In outbreaks of fascioliasis each animal in the flock should be injected immediately the presence of the disease is recognized, repeating treatment as necessary throughout the period when infestation is occurring, at intervals of not less than one month. On farms with fluke-infested pastures, routine preventative dosing should be carried out at intervals of not less than one month, having regard for such factors as the past disease history of the farm, the frequency and severity of neighboring outbreaks and regional forecasts of incidence. The treatment of cattle helps to reduce contamination of pastures on farms where fascioliasis is endemic or certain round worm occurrence in evident.

\section{Pharmacokinetics of nitroxynil}

Injected nitroxynil binds very strongly and almost completely ( $>97 \%)$ to plasma proteins. Concentrations in blood are substantially higher than in the tissues. Nitroxynil is excreted mostly unchanged through the liver and its metabolites are eliminated by feces through the bile route, this is why high concentrations are found in the bile ducts, the preferential sites of adult liver flukes. It is also metabolized in the liver parenchyma to a metabolite that has also flukicidal activity, which explains its efficacy against late immature flukes that migrate through the liver tissues (Junquera, 2014). Biotransformation of nitroxynil is rather slow and occurs mainly in the gastrointestinal tract and liver. Nitroxynil was shown to be metabolized by hydrolysis of the cyano group to produce 3-iodo-4-hydroxy-5 nitrobenzamide and 3-iodo-4-hydroxy-5-nitrobenzoic acid in rat liver. The enzyme(s) responsible for this hydrolytic reaction was primarily localized in the cytosol (Markus and Kwon, 1994). Nitroxynil was also found to be nitroreduced in rat liver into 3-iodo-4-hydroxy-5-aminobenzonitrile (MaffeiFacino et al., 1982). Further methylation of this metabolite into 3-iodo-4-methoxy-5- aminobenzonitrile was also shown. However, the inactive metabolites were not detected in the urine nor in the plasma of nitroxynil treated sheep. Indeed, unchanged drug is likely to be the only source responsible for nitroxynil action. High plasma protein binding favoring the distribution of the drug to the tissues and its slow elimination of the organism, suggesting that, the blood is the primary source of drug uptake via the fluke's digestive system. In addition, the levels of nitroxynil in bile are far lower than those observed in plasma and so, the uptake of this anthelmintic through the tegument would be limited (McKinstry et al. 2003). Given the low percentage of parent substance found in the liver and kidney while the percentage in plasma and muscle and fat remained particularly high, it can be concluded that the Nitroxynil extensively metabolized in liver and the metabolites are very quickly eliminated by renal excretion (EPMAR, 2012). Besides, the primary urinary route of elimination, nitroxynil is also excreted in feces and milk. Animals can be slaughtered for human consumption 60 days after nitroxynil treatment. Nitroxynil also stains wool or hair yellow; thus, care must be exercised to avoid spilling. The drug is well tolerated in cattle and sheep at the therapeutic dose of $10 \mathrm{mg} / \mathrm{kg}$. Nitroxynil side effects in these species include hyperthermia and hypercapnea, which were associated with the uncoupling of oxidative phosphorylation in the target species and observed at higher dose levels. Doses above $40 \mathrm{mg} / \mathrm{kg}$ may be lethal. Other nitrophenolic flukicidal compounds such as disophenol and niclofolan were replaced by nitroxynil and many other newer and safer fasciolicidal drugs. It is possible to confirm its inhibiting effects on oxidative phophorylation over Fasciola gigantica in laboratory conditions, after adding 20 $\mathrm{mg} / \mathrm{mL}$ in vitro, which induces the immediate stop of the muscular contractions, making think that acts neuromuscular blocker, due to this the parasite dies paralyzed and with energy deficiency. The drug is used by parental route because in the rumen would suffer efficiency reduction; the maximum plasmatic levels are acquired between 30 and 60 minutes and the mean life is 8 days. Various other studies realized with nitroxynil demonstrates that effective blood levels are reached after 5 hours of the drug's administration and with maximum peaks after 12 hours, with an activity threshold during 30 days that maximizes it antiparasitication. Excretion through feces and urine is quite slow as well, and takes about 30 days to be completed. Excretion half-life in sheep and cattle is about 5-8 days. This slow rate of elimination is in accordance with the observed long duration of action of nitroxynil against fluke in sheep and cattle. After oral administration, microorganisms in the rumen break it down to ineffective compounds. This is why injectables are preferred over drenches.

\section{Mechanism of action of nitroxynil}

Nitroxynil is an uncoupler of the oxidative phosphorylation in the cell mitochondria of the helminthes, which disturbs the production of ATP, the cellular fuel. The drug impedes to use the oxide-reduction reactions for adenosine triphosphate (ATP) production resulting impairment of the parasites motility and probably other processes as well. As a result after the use of all its energetic reserves the parasites die due to starvation. The drug causes swelling and severe disruption of the tegumental surface of parasites as well as swelling of the basal in-folds in the tegumental syncytium, edematous flooding of the parenchyma, and mitochondrial deformation in the syncytium and tegumental cells (McKinstry, 2008, McKinstry et al., 2009). Disruption to the spines anterior mid-body region, directly behind the ventral sucker, widespread swelling, blebbing and extensive furrowing of the tegument, and the spines seems to be a particular feature of Nitroxynil action. Due 
to the action of nitroxynil, the thin tegument covering the spines splits and sloughs off and the spines are lost, the holes thus formed in the syncytium allow more access of the drug to internal tissues. Disruption occurs more in the dorsal surface on the anterior than on the posterior region of the fluke resulted from higher exposure to the drug as the flukes are folded ventrally when in the bile ducts. This becomes especially promoted by the surfactant action of bile in vivo (Ichhpujani et al., 2002, McKinstry et al., 2003, Fairweather et al., 1984). This drug also causes the scolex detachment of the intestinal mucosa and the proximal proglottid of the cestode.

\section{Adverse reactions and interactions with provisions of nitroxynil}

No systemic ill effects are to be expected when animals including pregnant cows and ewes are treated at normal dosage. Side effects of nitroxynil are possible, but don't always occur. Small swellings are occasionally observed at the injection site in Cattle. These can be avoided by injecting the dose in two separate sites and massaging well to disperse the solution. The side effects such as skin irritation; eye irritation may be rare but serious. Nitroxynil is four times safer than the therapeutic dose. In the event of accidental overdose or adverse reaction, the symptoms include hyperthermia, hyperpnoea, hypercapnea and increased excitability and high blood pressure. The animal with toxicity should be kept cool, and dextrose saline ought to be administered intravenously. Dairy cows should be treated at drying or at least 30 days before calving. As nitroxynil passes in the milk, it is better avoiding it in lactating cows. Ewes in advanced pregnancy should be driven, handled and dosed carefully. The drug should not be used in animals with known hypersensitivity as well as not be injected by mixing with any other preparations. No signs of incompatibility were observed when nitroxynil was administered to cattle or sheep concurrently with therapeutic doses of other anthelmintics like levamisole or thiabendazole. The usual withdrawal period of nitroxynil for meat is 30 days and milk for 5 days.

\section{Strategies against Drug Resistance}

Resistance to anthelmintics amongst helminth parasites is a global problem of increasing concern. A number of strategies suggested by Fairweather et al. (1999a) could be employed that may help to avoid or at least slow down the development and spread of anthelmintic resistance. They include limiting the number of anthelmintic treatments; strategic dosing at particular times of the year, based on epidemiological data; correct dosage; and the annual rotation of anthelmintics, using drugs from different chemical groups. The latter strategy is designed to prevent the build-up of resistance to a particular class of anthelmintic and to minimize the passage of resistance genes early in the selection process. However, a more effective approach is to use combinations of drugs. It is particularly useful when development of resistance reduces the efficacy of an individual drug, but it retains its efficacy in synergistic combinations.

\section{Concluding remarks and future directions}

Finally, fasciolicides will remain as the main form of fluke therapy for the foreseeable future. At present, fascioliasis appears to be under control because effective drugs like Nitroxynil and others are available that could be an alternative in case of triclabendazole resistance and disease levels are not at epidemic proportions. Since its discovery more than 3 decades back researches reconfirmed that nitroxynil uncouples oxidative phosphorylation in the cell mitochondria and a drug wherever injectables are preferred over drenches. Drug resistance does not appear to be a disastrous problem yet. The over-use of a particularly effective drug such as triclabendazole is inevitably leading to the problems of resistance. Judging from the nematode experience, it is vital to detect resistance early, because the resistance can only be detected when it is already beyond the point where reversion to susceptibility is possible (Roos et al., 1995). Nitroxynil has essentially remained a drug of choice in veterinary medicine for many decades but still much to learn about this essential anthelmintic. Since triclabendazole is becoming more and more resistant to liver flukes so nitroxynil and other flukicides such as closantel, rafoxanide, clorsulon and oxyclozanide are becoming key to address the issue of treatment of fascioliasis in livestock. Meanwhile, we should try to make the most effective use of existing drugs such as nitroxynil alone or in combinations with triclabendazole which might play an important role in the treatment of immature and adult fluke infections, continue to refine the design of management strategies and examine alternative options such as vaccines.

\section{REFERENCES}

1. Alvinerie M, Floc'h R and Galtier P (1991). Plasma protein binding of nitroxynil in several species. Journal of Veterinary Pharmacology and Therapeutics 14: 170-173.

2. Bishop Y, editor (2005). The veterinary formulary. 6th ed. London: Pharmaceutical Press; p. 199.

3. Boray JC (1967). Studies on experimental infections with Fasciola hepatica, with particular reference to acute fascioliasis in sheep. Annals of Tropical Medicine and Parasitology 61: 439-450.

4. Boray JC, Crowfoot PD, Strong MB, Allison JR, Schellenbaum M, Von Orelli M and Sarasin G (1983). Treatment of immature and mature Fasciola hepatica infections in sheep with triclabendazole. Veterinary Record 113: 315-7. 
5. Boray JC and Happich A (1968). Standardized chemotherapeutical tests for immature and mature Fasciola hepatica infections in sheep. Australian Veterinary Journal 44: 72-78.

6. Chen MG and Mott KE (1990). Progress in assessment of morbidity due to Fasciola hepatica infection. Tropical Disease Bulletin 87: R1-R37.

7. Coles GC and Stafford KA (2001). Activity of oxyclozanide, nitroxynil, clorsulon and albendazole against adult triclabendazole-resistant Fasciola hepatica. Veterinary Record 148: 723-724.

8. EPMAR (2012). Nitroxynil extrapolation of MRLs to bovine and ovine milk. European public MRL assessment report. EMA/CVMP/813401/2011

9. Fairweather I, Holmes SD and Threadgold LT (1984). Fasciola hepatica: motility response to fasciolicides in vitro. Experimental Parasitology 57: 209-224.

10. Fairweather I and Boray JC (1999a).Fasciolicides: efficacy, actions, resistance and its management. The Veterinary Journal 158: 81-112.

11. Fairweather I and Boray JC (1999b). Mechanisms of Fasciolicide Action and Drug Resistance in Fasciola hepatica, In: Dalton, J.P. (Ed.) Fasciolosis. CABI, United Kingdom, pp. 225-276.

12. Ghoneim MM, El-Ries M, Hassanein AM and Abd-Elaziz AM (2006). Volta metric assay of the anthelminthic veterinary drug nitroxynil in bulk form and formulation at a mercury electrode. Journal of Pharmaceutical and Biomedical Analysis 41 : 1268-1273.

13. Ichhpujani RL and Bhatia R (2002). Medical parasitology. 3rd edn. New Delhi, India: Jaypee Brothers Medical Publishers, $2-$ 42.

14. Junquera P (2014). Nitroxynil-for veterinary use on cattle, sheep and goats against flukes and roundworms. Parasitipedia.Net; 19:37.

15. MaffeiFacino R, Pitre D and Carini M (1982). The reductive metabolism of the nitro aromatic flukicidal agent nitroxynil by liver microsomal cytochrome P450. II Farmaco; Edizione Scientifica 37: 463-474.

16. Maria MV, Maria RF, Nelida FP, Luciano CO, Coral CP and Francisco ARV (2010). Efficacy of nitroxynil against Fasciola hepatica resistant to triclabendazole in a naturally infected sheep flock. Parasitology Research 107: 1205-1211.

17. Markus B and Kwon C (1994). In vitro metabolism of aromatic nitriles. Journal of pharmaceutical Sciences 83: 1729-1734.

18. Massoud J (1990). Fascioliasis outbreak of man and drug test (triclabendazole) in Caspian Littoral, northern part of Iran, 1989. In Proceedings of the Seventh International Congress of Parasitology, Paris 1990. Bulletin de la Société Française de Parasitologie 8: 438.

19. McKinstry B, Brennan GP, Halferty L, Forbes AB and Fairweather I (2007). Ultrastructural changes induced in the tegument and gut of Fasciola hepatica after in vivo and in vitro drug treatment with nitroxynil (Trodax). Parasitology Research 101: 929-941.

20. McKinstry B, Halferty L, Brennan GP and Fairweather I (2009). Morphological response of triclabendazole-susceptible and triclabendazole resistant isolates of $F$. hepatica to treatment in vitro with nitroxynil (Trodax). Parasitology Research 104: 645-655.

21. McKinstry B, Halferty L, Brennan GP and Forbes AB (2003). Fasciola hepatica tegumental surface alterations following treatment in vivo and in vitro with nitroxynil (Trodax). Parasitology Research 91: 251-2 63.

22. McKinstry B (2008). Ultrastructural changes observed in Fasciola hepatica following treatment with nitroxynil and triclabendazole, alone and in combination [PhD thesis]. UK: the Queen's University of Belfast.

23. Mitchell GB, Maris L and Bonniwell MA (1998).Triclabendazole-resistant liver fluke in Scottish sheep. Veterinary Record 143: 399.

24. Moll L, Gaasenbeek CP, VellemaP and Borgsteede FH (2000). Resistance of Fasciola hepatica against triclabendazole in cattle and sheep in the Netherlands. Veterinary Parasitology 91: 153-158.

25. Mooney L, Good B, Hanrahan JP, Mulcahy G and de Waal T (2009). The comparative efficacy of four anthelmintics against a natural acquired Fasciola hepatica infection in hill sheep flock in the west of Ireland. Veterinary Parasitology 164: 201205.

26. Olaechea F, Lovera V, Larroza M, Raffo F and Cabrera R (2011). Resistance of Fasciola hepatica against triclabendazole in cattle in Patagonia (Argentina). Veterinary Parasitology 178: 364-366.

27. Omran EK and Ahmad NS (2015). Effect of nitroxynil (fasciolid) on adult Fasciola gigantica and Fasciola hepatica in infected cows. Parasitologists United Journal 8: 107-114.

28. Overend DJ and Bowen FL (1995). Resistance of Fasciolahepatica to triclabendazole. Australian Veterinary Journal 72: 275-276.

29. Rapic D, Dzakula N, Sakar D and Richards RJ (1998). Comparative efficacy of triclabendazole, nitroxynil and rafoxanide against immature and mature Fasciola hepatica in naturally infected Cattle. Veterinary Record 122: 59-62.

30. Roos MH, Kwa MSG and Grant WN (1995). New genetic and practical implications of selection for anthelmintic resistance in parasitic nematodes. Parasitology Today 11: 148-150.

31. Whelan M, Kinsella B, Furey A, Moloney M, Cantwell H, Lehotay SJ and Danaher M (2010). Determination of anthelmintic drug residues in milk using ultra high performance liquid chromatography-tandem mass spectrometry with rapid polarity switching. Journal of Chromatography A 1217: 4612-4622. 